\title{
Customer Retention: Behaviour Perspective Model of Ghanaian Telecommunication Industry Using Multinomial Regression Analysis
}

\author{
Nelson Doe Dzivor ${ }^{1}$, Frank B. K. Twenefour ${ }^{2 *}$, Emmanuel M. Baah², Mathias Gyamfi² \\ ${ }^{1}$ Department of Applied Mathematics and Statistics, Faculty of Applied Sciences, Accra Technical University, Accra, Ghana \\ ${ }^{2}$ Department of Mathematics, Statistics and Actuarial Science, Faculty of Applied Sciences, Takoradi Technical University, \\ Takoradi, Ghana \\ Email: ^nddzivor@ttu.edu.gh, ^frank.twenefour@ttu.edu.gh
}

How to cite this paper: Dzivor, N.D., Twenefour, F.B.K., Baah, E.M. and Gyamfi, M. (2022) Customer Retention: Behaviour Perspective Model of Ghanaian Telecommunication Industry Using Multinomial Regression Analysis. Applied Mathematics, 13, 5667.

https://doi.org/10.4236/am.2022.131005

Received: December 19, 2021

Accepted: January 18, 2022

Published: January 21, 2022

Copyright $\odot 2022$ by author(s) and Scientific Research Publishing Inc. This work is licensed under the Creative Commons Attribution International License (CC BY 4.0).

http://creativecommons.org/licenses/by/4.0/

\section{(c) (i) Open Access}

\begin{abstract}
To stay competitive, the mobile telecommunication companies spend millions of Ghana cedi each year on building long-term relationships with their customers. Marketing managers are constantly challenged with the problem of where to channel the limited resources in order to retain existing customers. This study approaches the customer retention problem in the mobile phone sector from a behavioural perspective, applying the Behavioural Perspective Model as the main analytical framework and further exploits some other factors that influence customer retention. The model includes a set of pre-behaviour and post-behaviour factors to study consumer choice, and explains its relevant drivers in a viable and comprehensive way, grounded in radical behaviourism. Data for the analysis were collected from tertiary students from Accra and Takoradi. Data collected were analysed using the multinomial regression technique. Analysis of the data revealed that the Behaviour setting factor is the only significant element in Behaviour Perspective Model. Further exploitation of behaviour situation revealed that the number of networks a customer uses, previous experience of a customer and customer's intention are significant factors in determining customer retention in Ghana's mobile telecommunication industry.
\end{abstract}

\section{Keywords}

Behavioural Perspective Model, Customer Retention, Ghana's Mobile

Telecommunication Industry, Multinomial Regression Technique 


\section{Introduction}

Customer loyalty/retention has been widely applauded and acknowledged as a valuable asset in competitive markets. Thus, having a satisfied and loyal customer is the ultimate aim of every business establishment. The effect of customer experience on future purchasing behaviour has been receiving much attention from many. This article is mainly aimed at investigating the effect of positive and negative experiences on repeat (switching) consumer purchase behaviour in the Ghana mobile phone sector; this was clearly illustrated by applying the Behavioural Perspective Model (BPM). The BPM is a proposed model developed by Foxall to give a clear explanation of consumer behaviour in a variety of situations [1]. The Ghana mobile telecommunication industry is one of today's most rapidly growing and competitive sectors. The importance of the mobile business has increased since it has now entered all aspects of life, including education, health, business, entertainment, et cetera. Over the last decade, the mobile industry has passed through a wave of critically rapid changes in its structure, competition, strategies, techniques, and technological environment. The competition has grown to the extent that the active mobile lines in Ghana as of November 2012 was $100.41 \%$ of the estimated population which stood at $25,344,745$ [2]. Subscribers may, for instance, switch to other networks depending on the extent of their loyalty or their perceived satisfaction with the value they get from products and services. Moreover, customers in Ghana now have the added option of porting their telecommunication numbers to other networks if they so desire. This challenge is further compounded with the technology of multiple SIM phones. This has made it imperative for the telecommunication networks to institute promotions and strategies that promote their brands as well as increase, sustain and reward loyal customers.

This article concerns an investigation into how to retain mobile service users and enhance their future usage of such services in the telecommunication industry in Ghana. Accordingly, this research provides both theoretical and empirical explanations of customer retention behaviour by applying the behavioural perspective model proposed by [1] [2]. The main objectives of this article are to determine the extent to which behaviour perspective model can be used to predict customer retention behaviour in the Ghana telecommunication industry; to examine which factors drive customer retention behaviour in the Ghana telecommunication industry, and to examine how the Behaviour Perspective Model can be used to explain customer retention behaviour in mobile phone context in Ghana telecommunication industry.

\section{Materials and Methods}

Exploratory research was conducted using random target population for generalizability of the results to study customer's choice and behaviour situation. Data in this study were collected from pre-paid (Pay-as-you-go) mobile subscribers using a structured questionnaire and self-administered to the respondents [3]. 
Data was captured using CSPRO and analysed using Statistical Package for Service Solution, version 25 and Minitab, version 16.

\subsection{Logistic Regression}

Logistic regression is a mathematical modeling approach that can be used to describe the relationship of several independent variables to a dichotomous dependent variable. The response variable in logistic regression is usually dichotomous, that is, the response variable can take the value 1 with a probability of success $(p)$, or the value 0 with probability of failure $(1-p)$, [4] [5]. The Logistic function describes the mathematical form on which the Logistic model is based [6] [7]. The Logistic function $(z)$ is given by:

$$
f(z)=\frac{1}{1+\mathrm{e}^{-z}} \text { where } z=\alpha+\beta_{1} X_{1}+\beta_{2} X_{2}+\cdots+\beta_{n} X_{n}=\alpha+\sum_{i=1}^{n} \beta_{i} X_{i}
$$

and

$$
\begin{gathered}
X_{1}, X_{2}, \cdots, X_{n} \text { are independent variables hence } f(z)=\frac{1}{1+\mathrm{e}^{-\left(\alpha+\sum_{i=1}^{n} \beta_{i} X_{i}\right)}} \\
\log \left[\frac{P_{i}}{1-P_{i}}\right]=\alpha+\beta_{1} X_{i 1}+\beta_{2} X_{i 2}+\cdots+\beta_{k} X_{i k}
\end{gathered}
$$

The expression on the left-hand side is usually referred to as the Logit or Logodds [7] [8]. The Logit equation can be solved to obtain (see Equation (4))

$$
P_{i}=\frac{\exp \left(\alpha+\beta_{1} X_{i 1}+\beta_{2} X_{i 2}+\cdots+\beta_{k} X_{i k}\right)}{1+\exp \left(\alpha+\beta_{1} X_{i 1}+\beta_{2} X_{i 2}+\cdots+\beta_{k} X_{i k}\right)}
$$

In general, maximizing the likelihood function $L(\theta)$ is equivalent to maximizing $\ln L(\theta)$ which is computationally easier [8]. That is by solving:

$$
\frac{\partial \ln L(\theta)}{\partial \theta_{j}}=0, \quad j=1,2, \cdots, q
$$

Consider customer retention study to investigate customer's retention behaviour. The response variable has three mutually exclusive and collectively exhaustive outcomes. Thus;

$$
Y= \begin{cases}1 & \text { if promoter } \\ 2 & \text { if passive } \\ 3 & \text { if detractor }\end{cases}
$$

In ungrouped form, the response occupies a single column of the dataset, but in grouped form, the response occupies $r$ columns. Most computer programs for polychotomous logistic regression can handle grouped or ungrouped data. Whether the data are grouped or ungrouped, we will imagine the response to be multinomial [6] [7] [8]. That is, the "response" for row i is

$$
Y_{i}=\left(Y_{1}, Y_{2}, \cdots, Y_{i r}\right)^{\mathrm{T}}
$$

is assumed to have a multinomial distribution with index 


$$
n_{i}=\sum_{j=1}^{r} y_{i j}
$$

and the parameter

$$
\pi_{i}=\left(\pi_{1}, \pi_{2}, \cdots, \pi_{i r}\right)^{\mathrm{T}}
$$

If the data are grouped, then $n_{i}$ is the total number of "trials" in the $I^{\text {th }}$ row of the dataset, and $y_{i j}$ is the number of trials in which outcome $j$ occurred [8]. If the data are ungrouped, then $y_{i}$ has a 1 in the position corresponding to the outcome that occurred and 0 's elsewhere, and $n_{i}=1$.

\subsection{Multinomial Regression Model}

The generalized linear modelling technique of multinomial logistic regression can be used to model unordered categorical response variables. This model can be understood as a simple extension of logistic regression that allows each category of an unordered response variable to be compared to an arbitrary reference category providing a number of logit regression models. In this study, the dependent variable has three response categories namely promoters, passive and Detractors. Hence there would be two logit equations that would be fit simultaneously. In studying consumer behaviour, an individual is presented with a set of alternatives and asked to choose the most preferred alternative. Multinomial logistic regression allows each category of an unordered response variable to be compared to a reference category, providing a number of logistic regression models. For example, the model which of three behaviour situations (there are three categories in the unordered response variable) is likely to be chosen by a customer, two logit models are computed; one comparing behaviour A (promoter) with the reference category $C$ (passive) and one comparing behaviour B (detractor) with the reference category $\mathrm{C}$ (passive). The coefficients of the predictors (of the logistic model) are conditionally modeled based on the membership of cases to a particular stratum. Marginal logistic modeling refers to an aggregation of the strata so that the coefficients reflect the population values averaged across the strata. As a rudimentary example, consider averaging each of the conditional logistic coefficients, from the previous paragraph, to arrive at set marginal coefficients for all members of the population-regardless of strata membership [7] [8].

$$
\begin{aligned}
& \ln \frac{\operatorname{prob}\{Y=\text { promoter }\}}{\operatorname{prob}\{Y=\text { passive }\}}=\alpha+\beta_{1} X_{1}+\beta_{2} X_{2}+\cdots+\beta_{k} X_{k} \\
& \ln \frac{\operatorname{prob}\{Y=\text { detractor }\}}{\operatorname{prob}\{Y=\text { passive }\}}=\alpha+\beta_{1} X_{1}+\beta_{2} X_{2}+\cdots+\beta_{k} X_{k}
\end{aligned}
$$

In the multinomial Logit model, we assume that the log-odds of each response follow a linear model

$$
\mu_{i j}=\ln \frac{\operatorname{prob}\{Y=j\}}{\operatorname{prob}\left\{Y=j^{\prime}\right\}}=\alpha_{j}+X_{j}^{\prime} \beta_{j}
$$




\section{Results and Discussion}

Examination of data discovered that there is a significant association between the number of networks a respondent has and the main current network a respondent use (as p-value 0.009 is less than $5 \%$ ). It is significant to note that $14.64 \%$ of the respondents use three or more networks. $47.86 \%$ use two networks and $37.5 \%$ use only one network. Again, the data revealed that $53.21 \%$ of the respondents use MTN as their main network while $45.79 \%$ use other networks. It is also quite clear that there is a significant association between how long a person uses a network and the type of network the person uses as the main current network (as $p$-value, 0.016 is less than 0.05). It is quite clear that there is an association between "the current main network" and "customer behaviour situation" (since $p$-value, 0.019 is less than the level of significance-which is 0.05 ). This shows clearly that whether the customer is a detractor or passive or promoter has something to do with the network he/she is using as his/her main network. About $15 \%$ of the respondents will continue to serve as ambassadors for their current main network to their family and friends while about $85 \%$ of them either don't care whether their family and friends join them or not, or will not recommend the network to their family and friends

\subsection{The Multinomial Logistic Regression}

It has already been mentioned that multinomial regression is used to analyse study factors in situations where the aim is to predict one variable on the basis of several independent factors. It was used to help identify which of the independent variables are significantly affecting behaviour situations. The model that was ultimately tested is:

$$
\mathrm{CR}=\alpha+\beta_{1}(\mathrm{BS})+\beta_{2}(\mathrm{UR})+\beta_{3}(\mathrm{UP})+\beta_{4}(\mathrm{IR})+\beta_{5}(\mathrm{IP})
$$

where:

UR = Utilitarian Reinforcement,

UP = Utilitarian Punishment,

IR = Informational Reinforcement,

IP = Informational Punishment,

$\mathrm{BS}=$ Behaviour Setting.

And $\alpha, \beta_{1}, \beta_{2}, \beta_{3}, \beta_{4}, \beta_{5}$ are constants to be estimated from data.

According to [9], behaviour Setting factor is only a significant component of Behaviour Perspective Model that influences customer retention and all other components can be done without.

To be able to estimate the marginal effect of BPM component on customer retention, two set of multinomial logistic equations (Table 1 and Table 2 referred) below are estimated as:

$$
\begin{aligned}
& \ln \frac{\operatorname{prob}\{Y=\text { promoter }\}}{\operatorname{prob}\{Y=\text { passive }\}}=\alpha+\beta_{1}(\mathrm{BS})+\beta_{2}(\mathrm{UR})+\beta_{3}(\mathrm{UP})+\beta_{4}(\mathrm{IR})+\beta_{5}(\mathrm{IP}) \\
& \ln \frac{\operatorname{prob}\{Y=\text { detractor }\}}{\operatorname{prob}\{Y=\text { passive }\}}=\alpha+\beta_{1}(\mathrm{BS})+\beta_{2}(\mathrm{UR})+\beta_{3}(\mathrm{UP})+\beta_{4}(\mathrm{IR})+\beta_{5}(\mathrm{IP})
\end{aligned}
$$


Table 1. Likelihood ratio tests.

\begin{tabular}{ccccccc}
\hline & \multicolumn{3}{c}{ Model Fitting Criteria } & \multicolumn{2}{c}{ Likelihood Ratio Tests } \\
\cline { 2 - 7 } Factors & $\begin{array}{c}\text { AIC of } \\
\text { Reduced } \\
\text { Model }\end{array}$ & $\begin{array}{c}\text { BIC of } \\
\text { Reduced } \\
\text { Model }\end{array}$ & $\begin{array}{c}-2 \text { Log } \\
\text { Likelihood of } \\
\text { Reduced Model }\end{array}$ & Chi-Square & df & Sig. \\
\hline Intercept & 581.569 & 618.199 & 561.569 & 6.400 & 2 & 0.041 \\
BS & 584.666 & 621.296 & 564.666 & 9.497 & 2 & 0.009 \\
IR & 575.331 & 611.961 & 555.331 & 0.162 & 2 & 0.922 \\
UR & 577.413 & 614.043 & 557.413 & 2.244 & 2 & 0.326 \\
UP & 576.218 & 612.847 & 556.218 & 1.049 & 2 & 0.592 \\
IP & 575.775 & 612.405 & 555.775 & 0.606 & 2 & 0.739 \\
\hline
\end{tabular}

Table 2. Parameter estimates.

\begin{tabular}{lccccc}
\hline Customer Behaviour Situations & B & Wald & $p$-value & Odd Ratio \\
\hline & Intercept & 0.594 & 0.411 & 0.522 & \\
& BS & -0.150 & 6.369 & 0.012 & 0.861 \\
Detractor (Det) & IR & 0.020 & 0.159 & 0.690 & 1.020 \\
& UR & -0.077 & 1.068 & 0.301 & 0.926 \\
& UP & 0.045 & 0.810 & 0.368 & 1.046 \\
& IP & 0.031 & 0.315 & 0.575 & 1.031 \\
\hline \multirow{3}{*}{ Promoter (Pro) } & Intercept & -2.604 & 4.308 & 0.038 & \\
& BS & 0.064 & 0.605 & 0.437 & 1.066 \\
& IR & 0.005 & 0.005 & 0.942 & 1.005 \\
& UR & 0.069 & 0.462 & 0.497 & 1.071 \\
& UP & -0.011 & 0.029 & 0.864 & 0.989 \\
& IP & 0.049 & 0.470 & 0.493 & 1.051 \\
\hline
\end{tabular}

It can be observed from the table (Table 1) that the estimated coefficients for BS, UR, IR, and IP are all positive; meaning that these variables contribute to promoter behaviour situation and hence contribute positively to customer retention. Meanwhile, the coefficient of UP is negative implies that Utilitarian Punishment is a factor that deepens the passive behaviour situation of customers. This, essentially, is contributing negatively to customer retention.

From the table, we have the logit equation as:

$$
\begin{aligned}
& \ln \frac{\operatorname{prob}\{Y=\text { promoter }\}}{\operatorname{prob}\{Y=\text { passive }\}} \\
& =-2.604+0.064(\mathrm{BS})+0.069(\mathrm{UR})-0.011(\mathrm{UP})+0.005(\mathrm{IR})+0.049(\mathrm{IP})
\end{aligned}
$$

The estimated coefficient of 0.064 for Behaviour setting means if the BS vari- 
able increases by one unit the logit of promoter referencing passive would increase by 0.064 units while controlling other variables. This means that the likelihood of a customer to continue promoting the current network usage will increase by 0.064 points given a unit increase in the BS factor. Also, a unit increase in the UR variable will result in corresponding 0.069 increases in the multinomial logit of promoter referencing passive. However, when UP increases by one unit, $\ln \left\{\frac{p \text { (promoter })}{p \text { (passive) })}\right\}$ will decrease by 0.011 .

Also, a unit increase in IR and IP will result in 0.005 and 0.049 increase in $\ln \left\{\frac{p \text { (promoter })}{p \text { (passive) }}\right\}$ respectively (see Table 2 ).

In testing the null hypothesis that none of the coefficients is significantly different from zero, a look at the $p$-value column of the table above and reveal that none of the values for the coefficients of the independent variables is below 0.05. Since all the $p$-values are above the level of significance, we fail to reject the null hypothesis that all the coefficients of independent variables are not different from zero. This implies that there is no sufficient evidence to conclude that the coefficient of all the predictor variables is significantly different from zero. In other words, none of the predictor variables has (and would have) any influence on a customer who is a promoter. From odds ratio column, odds ratio for the BS variable being 1.066 implies that given the brand name of the network provider, good customer services and easy accessibility to customer service, a customer is 1.066 times likely to be a promoter than a passive.

From the odd ratio column, odds ratio for IR variable being 1.005 implies that given the feeling of safety and security, network's effect of improving relationship with others, family and friend's recommendation to continue using the network and advertisement; a customer is 1.005 times likely to be a promoter than a passive. Also, Odd Ratio for the UR variable being 1.071 implies that given promotions and bonuses and superior products and services; a customer is 1.071 times likely to be a promoter than a passive. Odd ratio for UP variable being 0.989 implies that given the too expensive nature of doing business with the network, too inconvenient of switching to another network and no better alternative network; a customer is 0.989 times (less) likely to be a promoter than a passive. Again, OR for IP variable being 1.051 implies that given the feeling that the network provider does not take customer's complaint seriously and customer's right to privacy and confidentiality is not protected; a customer is 1.051 times (more) likely to be a promoter than a passive.

The second logit equation is

$$
\begin{aligned}
& \ln \frac{\operatorname{prob}\{\text { detractor }\}}{\text { prob }\{\text { passive }\}} \\
& =0.594-0.15(\mathrm{BS})-0.077(\mathrm{UR})+0.045(\mathrm{UP})+0.02(\mathrm{IR})+0.031(\mathrm{IP})
\end{aligned}
$$

From the equation above, the coefficients of BS and UR being negative means 
that Behaviour Setting and Utilitarian Reinforcement factors independently reduce detractors' behaviour situation. This means that BS (increasing branding, accessibility to customer care outlets and good customer experience service) and UR (increasing promotions and bonuses and superior products and services) increase customer retention. A unit increase in BS and UR variables (independently) will result in a decrease of $\ln \left\{\frac{p \text { (detractor })}{p \text { (passive })}\right\}$ by 0.150 and 0.077 units respectively. Positive sign of the coefficients of UP, IR and IP indicate that these variables would increase detractorship behaviour of a customer and hence reducing customer retention.

A unit increase in UP, IR and IP (when controlling other factors) independently will cause increase in $\ln \left\{\frac{p \text { (detractor })}{p \text { (passive })}\right\}$ by $0.045,0.020$ and 0.031 respectively.

This means that the tendency of a customer to be a detractor can be reduced by the Behaviour Setting factor (brand name, good customer service, and easy accessibility) and the Utilitarian factor (promotions and bonuses, and superior products and services).

But this tendency rather increases by Utilitarian Punishment (expensiveness of doing business with the networks, inconvenience of switching to other networks, and no better alternative network), Informational Punishment (the feeling that the network provider does not take customer's complaint seriously and customer's right of privacy and confidentiality not protected) and Informational Reinforcement (feeling of safety and security, network's effect of improving relationship with others, family and friends recommendation to continue using the network and advertisement).

In testing the significance of this factor, the only factor that has its $p$-value less than 0.05 (level of significance) is Behaviour Setting (BS) - meaning that BS measures will significantly reduce the tendency of a customer being a detractor. As a result of the significance of this construct (BS), OR being 0.861 means that (given BS construct) a customer is 0.861 times (less) likely to be a detractor than a passive. Other factors which also been proven to be significantly contributing to customer retention are the number of networks used by subscribers, negative experience and customer's intention as depicted in Table 3 and Table 4 respectively. Having identified the variables that are significant to customer retention, the investigators deemed it appropriate to develop a statistical model for customer retention behaviour (otherwise known as behaviour situation).

\subsection{Customer with One Network}

This is the multinomial Logit estimate comparing a customer with only one network to a customer with more than one network given the other variables in the model are held constant. The multinomial Logit for a customer with only 
Table 3. Likelihood ratio tests.

\begin{tabular}{ccc}
\hline Effects & Chi-Square & $p$-value \\
\hline Intercept & 0.000 & \\
Number of networks a respondent has & 7.265 & 0.026 \\
Previous experience & 25.617 & 0.000 \\
Customer's intention & 9.101 & 0.011 \\
\hline
\end{tabular}

Table 4. Parameter estimates.

\begin{tabular}{cccccc}
\hline \multirow{2}{*}{ Customer Behaviour Situations } & B & Wald & $p$-value & $\begin{array}{c}\text { Exp (B) } \\
\text { (OR) }\end{array}$ \\
\hline \multirow{4}{*}{ detractor } & Intercept & -0.124 & 0.033 & 0.857 & \\
& Customer with one network & 0.097 & 0.083 & 0.774 & 1.102 \\
& Past negative experience & 1.263 & 6.547 & 0.011 & 3.537 \\
& Customer's plan to continue & -1.428 & 7.959 & 0.005 & 0.240 \\
\hline \multirow{3}{*}{ promoter } & Intercept & 0.781 & 0.891 & 0.345 & \\
& Customer with one network & -1.214 & 5.497 & 0.019 & 0.297 \\
& Past negative experience & -1.372 & 9.859 & 0.002 & 0.254 \\
& Customer's plan to continue & -0.720 & 0.878 & 0.349 & 0.487 \\
\hline
\end{tabular}

one network is 0.097 units higher than a customer with more than one network for being a detractor relative to passive given all other predictor variables in the model are held constant. This implies that a customer with only one network is more likely to be a detractor than a passive as compared to a customer with more than one network. This is confirmed by the Odds Ratio of 1.102. However, whether or not a customer has one network or not is not statistically significant in differentiating between a passive and a detractor ( $p$-value $=0.774$ which is more than 0.05); but it is significant in differentiating a promoter and a passive customer ( $p$-value $=0.019$ which is less than 0.05). Also, log Odds for a customer with only one network is $(-) 1.214$ units lower than a customer with more than one network for being a promoter relative to passive given all other predictor variables in the model are held constant. This means that a customer using only one network is less promoter-like than passive. The odd ratio which is $0.297 \mathrm{im}$ plies that the probability of a customer being a promoter given he/she has only one network is 0.297 times of being passive. This means that a customer who has only one network is 3.37 times passive rather than being a promoter as compared to a customer with more than one network.

\subsection{Customer's Past Negative Experience}

This is a Logit estimate comparing a customer with a past negative experience with the current main network to a customer with no past negative experience 
with the main current network given the other variables in the model are held constant. This particular variable is a statistically significant factor in both Logit equations (since the $p$-values 0.011 and 0.02 are less than alpha value 0.05 ). The $\log$ odds for a customer with past negative experience is 1.263 units higher than a customer with no past negative experience for being a detractor relative to passive given all other predictor variables in the model are held constant while that of promoter relative to passive is (-)1.372 lower. This implies that a customer with a past negative experience with the current main network is more likely to be a detractor than a passive as compared to a customer with no past negative experience. This is confirmed by the Odds Ratio of 3.537. This implies that the probability of a customer being a detractor is 3.537 times of being passive given he or she has a past negative experience with the current main network.

Also, log Odds for a customer with a past negative experience with the current main network is 1.214 units lower than a customer with no negative past experience with the current main network for being a promoter relative to passive given all other predictor variables in the model are held constant. This means that negative experiences would significantly make more passive behaviour situations from promoter behaviour. The odds ratio is 0.254 implies that the probability of a customer being a promoter given he/she has a negative experience with the current network is 0.254 times of being passive. The hypothesis that a customer's past negative experience has negative effect on customer retention is supported significantly by the data (as the $p$-value of 0.002 is less than $0.05)$.

\subsection{Customer's Intention to Continue}

Attention is turned on the Logit estimate comparing a customer's intention to continue using the current main network for the next two years to a customer with no such intention given the other variables in the model are held constant. This particular variable is statistically significant for detractor relative to passive (since $p$-value $0.005<0.05$ ) but not for promoter relative to passive (since $p$-value $0.349>0.05)$. The log odds for a customer who has an intention to continue using the main current network for the next two years is (-)1.428 units significantly lower than a customer with no such intention for being a detractor relative to passive given all other predictor variables in the model are held constant while that of promoter relative to passive is $(-) 0.720$ insignificantly lower. This is confirmed by the Odds Ratio of 0.240 . This implies that the probability of a customer being a detractor is 0.240 times of being passive given he or she has an intention to continue with the current main network for the next two years. It can be concluded that this variable is statistically instrumental in translating a detractor behaviour situation to a passive behaviour situation

\section{Conclusion}

A thorough investigation of the main mobile phone contract elements was conducted in this research to give an idea of the variety of utilitarian reinforcements 
that are essential for a deeper understanding of customers' choices (behaviour situations). These behaviour situations explain how suppliers maintain relationships with their customers to ensure they retain them, by administrating and selling these essential benefits. It is found that about $62 \%$ of customers have the intention of continuing to use their current main network for the next two years. This is quite lower than the $74.9 \%$ of the study sample who expressed their intention to renew contracts with their mobile operators as supported by [9] [10] [11]. Touching on customer's behaviour situation, only $15.3 \%$ of the study samples will continue using their main current network while about $85 \%$ are either passive or detractors. Such results are of value to industry players in terms of designing their marketing strategies to transform $40.3 \%$ of detractors through passive to promoters eventually; also, strategies to transform $44.4 \%$ of subscribers who are passive to promoters. This is very important because customers who are promoters are least likely to be attracted by competitors to switch. The researchers studied many of the suppliers' attributes that are directly linked to customers' interactions which in turn affect the customers' behaviour and retention. It is found out that there is a significant relationship between the main current network a respondent uses and the number of networks a respondent has. However, there is no relationship between the main network a respondent uses and the customer's intention to continue using the network for the next two years. The research has found out that whether a customer is a promoter or passive or detractor depends on the network the customer uses as the main current network. Notably, whether the customer is a promoter, passive or detractor for a given network has nothing to do with how long he/she is using that network as the main current network. The study further revealed that the behaviour settings factor is the only significant pre-behaviour retention driver. Participants illustrated that building social bonds with service firms' representatives is important and is seen as one of the most important functional techniques for retaining customers. Having a good brand name, good customer services and easy accessibility of customer care office is essential to the retention process because the majority of customers repeat their purchase behaviour out of loyalty to the service firm; this loyalty is kindled by the endeavours of the human resources personnel and the effects of interpersonal relationships with employees as supported by [9] [11] [12]. Having good customer experience services involves giving customers the best-in-class service always at any touchpoint, treating customers with courtesy, respect, and empathy.

\section{Authors' Contributions}

All authors contributed equally in relation to the study design, literature review, methodology, data collection, analysis and discussions, and the initial draft and final review of the manuscript. All authors read and approved the final manuscript.

\section{Conflicts of Interest}

We the authors declare that we have no competing interests whatsoever. 


\section{References}

[1] Foxall, G.R. (1992) The Behavioral Perspective Model of Purchase and Consumption: From Consumer Theory to Marketing Practice. Journal of the Academy of Marketing Science, 20, 189-198. https://doi.org/10.1007/BF02723458

[2] Myjoyonline Business Publication on February $4^{\text {th }}, 2013$. https://www.myjoyonline.com

[3] Tabachnick, B.G., Fidell, L.S. and Osterlind, S.J. (2001) Using Multivariate Statistics. Pearson Prentice Hall, Boston, MA.

[4] Hair, J.F., Black, W.C., Babin, B.J., Anderson, R.E. and Tatham, R. (2006) Multivariate Data Analysis. 6th Edition, Pearson Prentice Hall, Upper Saddle River, New Jersey.

[5] Agresti, A. (2000) An Introduction to Categorical Data Analysis. 2nd Edition, John Wiley and Sons, Hoboken, NJ.

[6] McFadden, D. (1974) Conditional Logit Analysis of Qualitative Choice Behavior. In: Zarembka, P., Ed., Economic Theory and Mathematical Economics, Academic Press, New York, NY, 105-142.

[7] Chatterjee, S. and Hadi, A.S. (2006) Regression Analysis by Example. 4th Edition, John Wiley and Sons, Hoboken, NJ. https://doi.org/10.1002/0470055464

[8] Freund, J.E. (2001) Mathematical Statistics. 5th Edition, Prentice-Hall, New Delhi.

[9] Baek, T.H., Kim, J. and Yu, J.H. (2015) The Differential Roles of Brand Credibility and Brand Prestige in Consumer Brand Choice. Psychology and Marketing, 27, $662-$ 678. https://doi.org/10.1002/mar.20350

[10] Chintagunta, P.K. (1999) Variety Seeking, Purchase Timing, and the "Lightning Bolt" Brand Choice Model. Management Science, 45, 486-498.

https://doi.org/10.1287/mnsc.45.4.486

[11] Alba, J.W. and Hutchinson, J.W. (2000) Knowledge Calibration: What Consumers Know and What They Think They Know. Journal of Consumer Research, 27, 123 156. https://doi.org/10.1086/314317

[12] Dorsch, M.J., Grove, S.J. and Darden, W.R. (2000) Consumer Intentions to Use a Service Category. Journal of Services Marketing, 14, 92-117.

https://doi.org/10.1108/08876040010309220 